\title{
A indústria de gás no Brasil: incertezas, implicações territoriais e perspectivas
}

Rosélia Piquet - Doutora em Teoria Econômica e Professora da Universidade Federal do Rio de Janeiro.

Elis Miranda - Geógrafa. Doutora em Planejamento Urbano e Regional. Professora/ Pesquisadora do Mestrado em Planejamento Regional e Gestão de Cidades da Universidade Candido Mendes-Campos.

\section{Resumen}

A indústria de gás natural tem assumido crescente importância no cenário latinoamericano. Este artigo objetiva discutir as mudanças econômicas e espaciais decorrentes da expansão dessa indústria no Brasil, provocadas pela crise no fornecimento do gás boliviano. O governo boliviano, ao nacionalizar, em maio de 2007, as reservas de gás natural, provocou efeitos negativos na economia brasileira, porque gerou uma crise de abastecimento. No entanto, a médio e a longo prazos, as mudanças no setor proporcionarão novas oportunidades de crescimento à economia brasileira, pois já se têm intensificado as pesquisas voltadas para novas descobertas e tem sido exigido o aumento da produção no território nacional.

\begin{abstract}
The natural gas industry has assumed increasing importance in the Latin American scene. This article aims to discuss the economic and spatial changes resulting from the expansion of this industry in Brazil, caused by the crisis in the supply of Bolivian gas. The Bolivian government to nationalize, in May 2007, the reserves of natural gas, caused negative effects on the Brazilian economy, because it generated a crisis of supply. However, the medium and long term changes in the industry will provide new growth opportunities to the Brazilian economy, because you already have intensified the research for new discoveries and has been required to increase production in the country.
\end{abstract}

\section{Palavras-chave}

Gás natural, indústria, crescimento econômico, Bolívia, Brasil.

\section{Keywords}

Natural gás, industry, economic growth, Bolívia, Brazil. 


\section{INTRODUÇÃO}

Dada a crescente importância que a indústria de gás natural tem assumido no cenário latino-americano, o objetivo do texto é discutir as mudanças econômicas e espaciais decorrentes da expansão dessa indústria no Brasil, provocadas pela crise no fornecimento do gás boliviano. Considera-se que o governo boliviano, ao nacionalizar, em maio de 2007, as reservas de gás natural, provocou de imediato efeitos negativos na economia brasileira, porque gerou uma crise de abastecimento; a médio e a longo prazos, porém, as mudanças no setor proporcionarão novas oportunidades de crescimento à economia brasileira, pois já se têm intensificado as pesquisas voltadas para novas descobertas e já se exige o aumento da produção no território nacional.

As novas oportunidades abertas pela expansão da produção interna de gás têm requerido (i) a implantação de ampla logística voltada para as etapas de exploração offshore e de distribuição, o que envolve a construção de gasodutos e dutos secundários, (ii) a expansão da indústria parapetrolífera graças às encomendas ao setor e (iii) uma maior integração entre as regiões brasileiras quanto à oferta de energia.

A situação energética do Brasil sempre foi privilegiada pelo leque de recursos disponíveis, tanto fósseis quanto renováveis. Desde os anos 50 do século XX, o eixo condutor das decisões da política energética nacional tem sido a permanente busca da redução da dependência externa, por meio da valorização dos recursos disponíveis no território nacional. Entretanto, o gás natural não fez parte das prioridades da política energética brasileira até o final dos anos 80; nesse caso, o Brasil trilhou um caminho inverso, fortemente ancorado nas importações bolivianas. O acordo firmado com a Bolívia em 1995 não era visto, a priori, como um problema, e a construção do gasoduto Bolívia-Brasil teve o mérito de concluir um longo processo de negociações entre os dois países.

O início das operações desse gasoduto em 1999 foi marcado pela insuficiência da demanda brasileira, tanto que no contrato de importação constavam cláusulas de take or pay (nos primeiros anos, pagava-se mesmo se nenhum gás fosse transportado ou comprado pelo Brasil), como forma de garantir os interesses bolivianos. Diante da baixa demanda interna pelo gás, tanto as empresas distribuidoras quanto a própria Petrobras buscaram, então, conquistar clientes industriais e estimular outros usos, como o do gás natural veicular. O agravamento da situação da geração hidroelétrica em 2001, provocada pela seca experimentada nas regiões Sudeste e Nordeste, favoreceu a instituição do Programa Prioritário de Termoelétricas (PPT), visto também como excelente oportunidade de ancorar 
a demanda de gás, pelo fato de as termoelétricas serem grandes consumidoras desse combustível.

Assim, em 1. ${ }^{\circ}$ de maio de 2006, quando o presidente boliviano Evo Morales anunciou a decisão de nacionalizar as reservas de gás natural e de exercer o controle das empresas do setor atuantes em solo boliviano, o fato assumiu enorme importância no Brasil. A diplomacia brasileira e, especialmente, a Petrobras - esta com imobilizações de cerca de 1,5 bilhão de dólares no país vizinho - viram-se diante de um novo cenário que exigia mudanças no discurso e nas ações.

A análise a seguir apresentada abrange o período de 1995 - data do acordo firmado com a Bolívia - até a atualidade, momento em que as crescentes tensões geopolíticas latino-americanas têm acelerado ainda mais as mudanças na indústria de gás no Brasil. As fontes consultadas são: (i) a Agência Nacional do Petróleo, Gás Natural e Biocombustíveis (ANP) e a Petrobras, no que se refere à produção de gás no Brasil e na Bolívia e ao mapeamento do setor do gás no Brasil, incluindo a distribuição dos gasodutos e a localização dos terminais de regaseificação; (ii) os dois jornais de maior circulação no Brasil - O Globo e O Estado de S. Paulo -, no que se refere à crise estabelecida entre esses países; (iii) estudos acadêmicos de especialistas em economia da energia.

\section{CARACTERÍSTICAS TÉCNICAS E ECONÔMICAS DA INDÚSTRIA DE GÁS NATURAL}

É sabido que o perfil do consumo e da oferta de energia tem-se modificado desde o fim da década de 70, quando as altas dos preços do petróleo em 1973 e 1978 - que se tornaram conhecidas como "choques do petróleo" - influenciaram a reorientação das políticas energéticas em praticamente todos os países do mundo. Desde então, a questão que surge nas sociedades industriais desenvolvidas diz respeito ao uso mais eficiente dos recursos energéticos. Essa maior eficiência pode ser obtida seja com a alteração das estruturas setoriais produtivas da economia, seja com a melhoria das técnicas produtivas ou ainda graças a mudanças comportamentais da sociedade. Na configuração das estruturas produtivas, a energia ocupa um lugar privilegiado, atuando na formação das vantagens competitivas de países, regiões e empresas; por isso existem fortes correlações entre política energética, política industrial e política exterior. A primeira dessas relações (energética/industrial) dá-se tanto pelo lado da construção da infraestrutura energética quanto pelo lado da construção do parque produtivo. As ligações entre política energética e relações internacionais explicitam-se pelo caráter geopolítico do suprimento de energia, dada a distribuição desigual dos recursos naturais entre as regiões do mundo, conforme indicado na Tabela 1. 
Tabela 1: Reservas provadas de gás natural no mundo (trilhões $\mathrm{m}^{3}$ ), segundo regiões geográficas.

\begin{tabular}{|l|r|r|r|}
\hline \multicolumn{1}{|c|}{ Regiões geográficas } & \multicolumn{1}{|c|}{$\mathbf{1 9 9 9}$} & \multicolumn{1}{c|}{$\mathbf{2 0 0 3}$} & \multicolumn{1}{c|}{$\mathbf{2 0 0 7}$} \\
\hline América do Norte & $\mathbf{7 , 3 2}$ & 7,38 & 7,98 \\
\hline Américas Central e do Sul & 6,81 & 6,82 & 7,73 \\
\hline Europa e ex-União Soviética & 60,41 & 60,17 & 59,41 \\
\hline Oriente Médio & 54,74 & 72,20 & 73,21 \\
\hline África & 11,43 & 13,94 & 14,58 \\
\hline Ásia-Pacífico & 12,18 & 13,24 & 14,46 \\
\hline Total & $\mathbf{1 5 2 , 8 9}$ & $\mathbf{1 7 3 , 7 5}$ & $\mathbf{1 7 7 , 3 7}$ \\
\hline
\end{tabular}

Fonte: www.anp.gov.br.

A diversificação das fontes de suprimento de energia, consequentemente, representa uma questão central no processo de planejamento dos países, envolvendo ações em diferentes áreas: econômica, tecnológica, ambiental, geopolítica e social. Tal diversificação tornou-se uma das estratégias mais importantes das políticas energéticas dos estados nacionais. Contudo, a história demonstra que a busca de fontes alternativas de energia é complexa, pois o setor energético reúne várias cadeias distintas, com fronteiras muito bem definidas para cada uma delas, com produtos, bases técnicas e mercados distintos. A concorrência entre o gás, o petróleo, o carvão e a hidroeletricidade, por exemplo, sempre ocorre a longo prazo, uma vez que qualquer mudança nos combustíveis implica investimentos ao longo de toda a cadeia produtiva. Mudar de combustível sempre significou mudar de equipamento. Só recentemente a pesquisa tecnológica tem proporcionado a construção de equipamentos flexíveis, quando começa a surgir uma geração de conversores de energia que operam com mais de uma fonte energética: caldeiras, motores e aquecedores que trabalham com mais de um combustível. Portanto, é só na atualidade que a competição passa a dar-se a curto prazo e os produtos de energia tornam-se substitutos próximos entre si (PINTO JUNIOR et al., 2007, p. 7).

Como indicado anteriormente, o gás natural não fez parte das prioridades da política energética brasileira até o final dos anos 80 . Só a partir da década de 90 adquire um novo status em função de dois fatores principais: a descoberta de importantes reservas de gás associado ao petróleo na Bacia de Campos e o avanço, a partir de 1994, das negociações para a importação de 30 milhões de $\mathrm{m}^{3}$ / dia de gás da Bolívia. O gás natural é encontrado associado ou não ao petróleo em bacias sedimentares, e seu aproveitamento, no segmento de exploração e produção (upstream), emprega basicamente as mesmas tecnologias que as do petróleo, uma vez que determinado reservatório pode revelar tanto petróleo 
quanto gás. Entretanto, embora seja considerado um combustível limpo, apresenta uma desvantagem básica, pois uma mesma quantidade de energia na forma de gás natural ocupa um volume cerca de 1000 vezes superior à energia na forma de petróleo. Daí ser a infraestrutura de transporte e de distribuição o segmento mais estratégico dos custos totais do produto para o consumidor final.

Seu transporte pode ser realizado de modos distintos: transporte por dutos, liquefeito ou comprimido. Essas três opções tecnológicas gerarão possibilidades igualmente distintas de integração espacial. A primeira das opções, o transporte por gasodutos, exige investimentos elevados e apresenta baixa flexibilidade. Os principais fatores que determinam o custo de sua construção são a extensão dos dutos, seu trajeto e o volume a ser transportado. Vale ressaltar que os custos de montagem e de desapropriação da área de servidão representam de 50\% a 60\% dos custos totais (PINTO JUNIOR et al., 2007, p. 238). Já o transporte do gás natural liquefeito é uma alternativa importante, quando não é viável técnica ou economicamente a construção de dutos. Exige plantas de liquefação e regaseificação, e o transporte de longa distância dá-se basicamente por navios metaneiros. Grande parte do mercado mundial do gás natural liquefeito concentra-se na Ásia, sendo o Japão o principal importador, com demanda de 43\% do gás mundial em 2004. Como as reservas de gás offshore tornaram-se significativas mundialmente, mas em boa parte formadas por campos dispersos que não permitem plantas de liquefação tradicionais, um grande esforço tecnológico tem sido feito para o desenvolvimento de unidades de liquefação menores, voltadas para a aplicação em alto-mar. Já a tecnologia de transporte do gás natural comprimido por cilindros não é recente e tem sido utilizada para servir nichos de mercado, tais como suprimento quando da interrupção do fornecimento por dutos, atendimento de demanda de pico, demanda veicular e, de modo geral, quando a rede de distribuição é incipiente e limitada às grandes cidades. Por seu elevado custo, é, das alternativas tecnológicas, a de menor utilização.

Como os custos de transporte por gasodutos caíram em até $60 \%$ desde 1985 - enquanto os do gás liquefeito limitaram-se a 30\% -, o transporte por dutos tornou-se mais competitivo até mesmo para distâncias superiores a 5.000 $\mathrm{km}$. Assim, o aumento da produção nacional e a viabilização da construção do gasoduto entre o Brasil e a Bolívia pareciam finalmente conferir bases sustentáveis à expansão da indústria de gás no Brasil, e é nessa época que a Petrobras expande suas atividades até o segmento upstream boliviano. Mas, em lugar de maior segurança energética, em 2004 surgem os primeiros sinais de crise no abastecimento, conforme apresentado a seguir. 


\section{A CRISE POLÍTICA NA BOLÍVIA E SEUS REFLEXOS NO BRASIL}

As condições econômicas e energéticas brasileiras e bolivianas são extremamente diversas, pois, enquanto o Brasil sempre foi privilegiado pelo leque de recursos disponíveis, tanto fósseis quanto renováveis, e conta com um parque industrial denso e complexo, a Bolívia é hoje um dos países mais pobres do mundo. Os dados da Tabela 2 evidenciam a desproporção entre os produtos nacionais de cada um desses países como também indicam que, enquanto a participação relativa do Brasil no total da América Latina tem aumentado de modo significativo, a da Bolívia declinou.

Tabela 2: Produto Interno Bruto da América Latina nos países selecionados (2002 e 2006).

\begin{tabular}{|l|r|r|r|r|}
\hline \multirow{2}{*}{ Países } & \multicolumn{2}{|c|}{2002} & \multicolumn{2}{c|}{2006} \\
\cline { 2 - 5 } & US\$ milhões & \multicolumn{1}{c|}{$\%$} & US\$ milhões & \multicolumn{1}{c|}{$\%$} \\
\hline Argentina & 102.040 & 5,9 & 214.058 & 7,3 \\
\hline Bolívia & 7.905 & 0,5 & 11.163 & 0,4 \\
\hline Brasil & 505.904 & 29,1 & 1.067 .962 & 36,3 \\
\hline Colômbia & 81.244 & 4,7 & 135.836 & 4,6 \\
\hline Equador & 24.899 & 1,4 & 40.800 & 1,4 \\
\hline México & 649.076 & 37,4 & 839.182 & 28,5 \\
\hline Peru & 57.056 & 3,3 & 93.269 & 3,2 \\
\hline Venezuela & 92.890 & 5,3 & 181.862 & 6,2 \\
\hline Demais países & 215.852 & 12 & 361.061 & 12 \\
\hline Total da América Latina & 1.736 .866 & 100 & 2.945 .193 & 100 \\
\hline
\end{tabular}

Fonte: Banco Mundial (fevereiro de 2008).

As experiências de reformas liberais que afetaram todos os países da América Latina levaram à privatização da Yacimientos Petrolíferos Fiscales Bolivianos (YBPF) entre 1995 e 1997 para as multinacionais do setor petrolífero (Enron, BG, BP, Shell, Repsol-YPF), por 3,4 bilhões de dólares no total. É no bojo dessas mudanças que têm início em 1996, em território boliviano, as operações da empresa Petrobras Bolívia e a construção do gasoduto Bolívia-Brasil (GASBOL). 


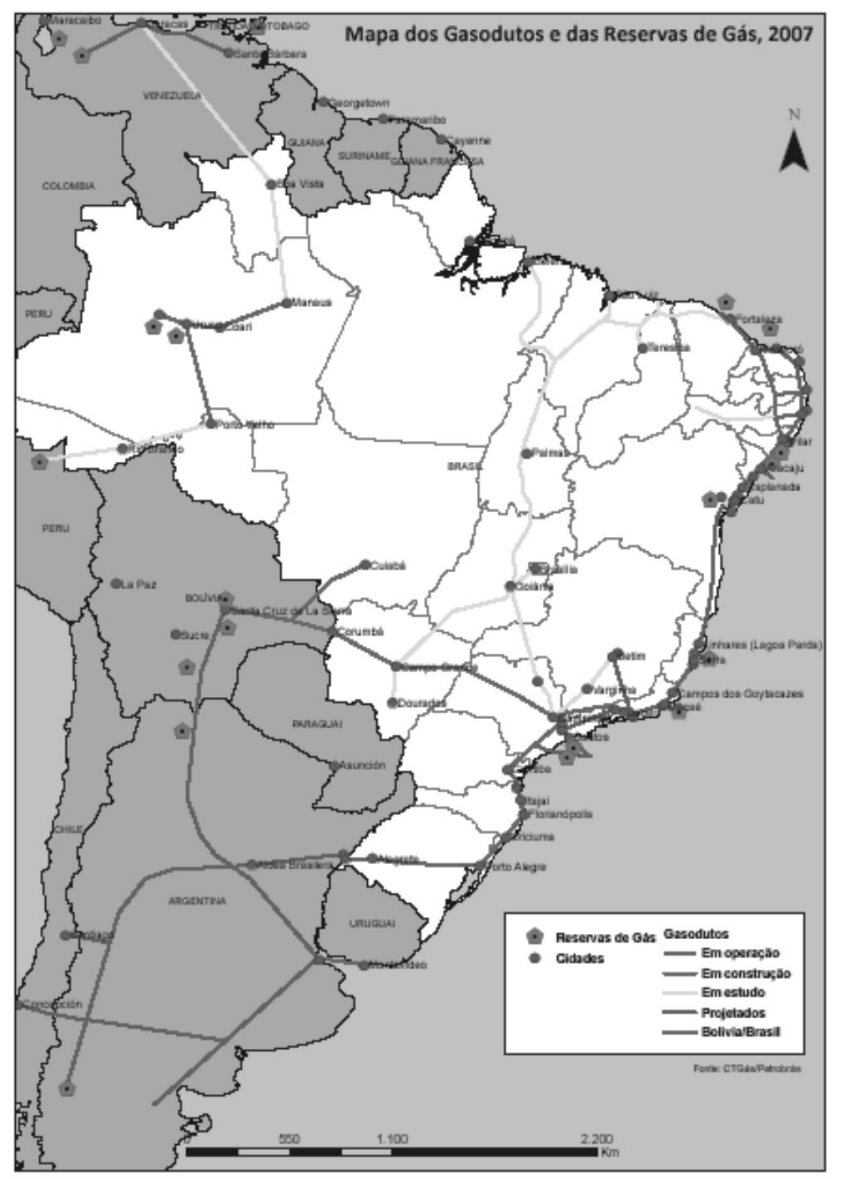

Mapa 1: Gasoduto Bolívia-Brasil.

A construção do gasoduto alterou substancialmente o fluxo comercial entre os dois países: enquanto em 1997 o valor total das trocas de óleo e gás resumia-se a US $\$ 70$ milhões, oito anos depois esse valor aproxima-se de US\$1 bilhão. Ainda: antes do fim das obras, em 1999, as exportações de hidrocarbonetos respondiam por $1 \%$ das exportações bolivianas e, em 2005, passam a representar $37 \%$ das vendas externas do país. Para o Brasil, mais da metade do gás consumido provém do país vizinho. São 30 milhões de metros cúbicos por dia em 45 milhões de consumo interno. Esse valor só não assume proporções alarmantes quando se considera o papel ainda reduzido do gás natural na matriz energética brasileira menos de 10\% do consumo final de energia (DUTRA, 2006, p. 8). Enquanto em 2005 o uso do gás na matriz energética brasileira representava 4,1\%, em 2007 atinge $9,6 \%$, sob o pressuposto de que não existiriam restrições de oferta - importada ou nacional - do produto. 
Assim, o anúncio do presidente boliviano Evo Morales da decisão de nacionalizar as reservas de gás natural e de exercer o controle das empresas do setor atuantes em solo boliviano - propondo alterações nas condições regulatórias e de operações da indústria de energia no país e uma revisão nos preços do gás pagos pela estatal brasileira - surpreendeu a diplomacia e especialmente a Petrobras, que se viram diante de novas regras de negociação. Quanto ao desejo do governo boliviano de aumentar sua participação nas rendas extraordinárias geradas pela exportação do gás natural, especialistas do setor reconhecem que o preço do gás importado da Bolívia situava-se entre os mais baratos e que o ajuste de preço solicitado pelo governo boliviano estaria de acordo com a realidade dos mercados energéticos mundiais. Como resultado, o mercado de gás natural passa a apresentar crescimento acelerado da demanda.

Como seria de esperar, alguns setores produtivos brasileiros ficaram descontentes com as posições assumidas pela diplomacia nacional, uma vez que o corte no fornecimento apresentou efeitos bastante diferenciados no território nacional. Nos estados de Mato Grosso, Mato Grosso do Sul, Paraná, Santa Catarina e Rio Grande do Sul, o consumo de gás é todo para uso térmico e em refinarias. Em Minas Gerais, metade do consumo é atendida pelo gás proveniente da Bolívia. A disponibilidade do gás boliviano e a instalação do gasoduto ligando a região produtora de gás na Bolívia à região mais industrializada no Brasil levaram o governo brasileiro a incentivar empresas do setor produtivo a alterarem sua base energética, utilizando o gás, o que pode ser verificado pelos dados da Tabela 3. Além disso, cerca de 1,5 milhão de carros brasileiros passou a utilizar o gás como combustível, visto que seu preço era sensivelmente inferior ao da gasolina.

Tabela 3: Consumo de gás natural no Brasil por setor (unidade: $10^{6} \mathrm{~m}^{3}$ ).

\begin{tabular}{|l|r|r|r|r|}
\hline & \multicolumn{1}{|c|}{1975} & 1985 & \multicolumn{1}{|c|}{1995} & \multicolumn{1}{c|}{2005} \\
\hline Consumo final & 414 & 2.539 & 4.435 & 15.044 \\
\hline Consumo final não energético & 92 & 948 & 956 & 849 \\
\hline Consumo final energético & 322 & 1.591 & 3.479 & 14.195 \\
Setor energético & 149 & 911 & 989 & 3.500 \\
Residencial & 0 & 0 & 52 & 217 \\
Comercial/público & 0 & 0 & 36 & 321 \\
Transportes & 0 & 0 & 49 & 1.945 \\
Industrial & 173 & 680 & 2.353 & 8.209 \\
\hline
\end{tabular}

Fonte: PINTO JUNIOR et al., 2007, p. 281.

Com a ameaça ao fornecimento de gás, criou-se no Brasil um clima de tensão e de pressão sobre o governo brasileiro e a Petrobras para que não aceitassem as 
imposições de Evo Morales. Contudo, a reação do governo brasileiro foi pró-ativa: em lugar de retaliações, foram adotadas medidas no sentido de levar o Brasil à maior independência em relação ao gás importado.

\section{A CONFIGURAÇÃO TERRITORIALDA INDÚSTRIA DE GÁS NATURAL NO BRASIL}

Dado o clima de instabilidade da oferta boliviana, em 4 de outubro de 2006, é lançado no Brasil o Plano de Antecipação da Produção de Gás Natural (PLANGÁS), tendo como objetivo o aumento de 24 milhões de $\mathrm{m}^{3} / \mathrm{d}$ de oferta de gás, o que elevaria a oferta para 40 milhões de $\mathrm{m}^{3} / \mathrm{d}$ no final de 2008 e para 55 milhões de $\mathrm{m}^{3} / \mathrm{d}$ em 2010. Portanto, a crise de abastecimento motivou a antecipação de projetos que já estavam em estudo, porém com um cronograma de execução mais alongado.

Essa aceleração da produção interna tem reconfigurado a espacialidade do setor do gás no Brasil, uma vez que envolve a logística de apoio às áreas de exploração offshore e onshore de transporte. A rede de gasodutos será ampliada, passando dos atuais $6.481 \mathrm{~km}$ para cerca de $9.000 \mathrm{~km}$ até 2009 , e o território nacional será cortado por uma rede de dutos, o que facilitará o processo de descentralização da produção industrial nacional.

No que se refere à espacialização da rede de distribuição de gás, o Brasil atua em três eixos distintos: Eixo Bolívia-Brasil, Eixo Centro-Sul e Eixo Nordeste (Mapa 2). O primeiro, conforme já especificado anteriormente, liga as reservas de gás na Bolívia a três macrorregiões brasileiras: Centro-Oeste, Sudeste e Sul. $\mathrm{O}$ segundo liga as principais reservas brasileiras às refinarias e ao maior mercado consumidor, constituído pelas indústrias localizadas em São Paulo. O terceiro eixo integra os estados do Ceará até a Bahia, distribuindo o gás das reservas localizadas nos estados da Bahia e do Sergipe às termoelétricas nordestinas.

Um dos principais trechos em construção da malha de gasodutos em território brasileiro é o Gasoduto Sudeste-Nordeste (GASENE), que ligará as reservas das bacias do Espírito Santo ao Estado do Rio de Janeiro e ao Estado da Bahia, completando a extensão total de 1.400 quilômetros. O trecho entre Vitória e Cabiúnas em Macaé (RJ), com uma extensão de 300 quilômetros, foi inaugurado em fevereiro de 2008 e transporta 5,5 milhões de $\mathrm{m}^{3} / \mathrm{d}$. O último e maior trecho do Gasene, ligando Cacimbas, no norte do Espírito Santo, a Catu, na Bahia, deverá ser entregue já em 2009. 


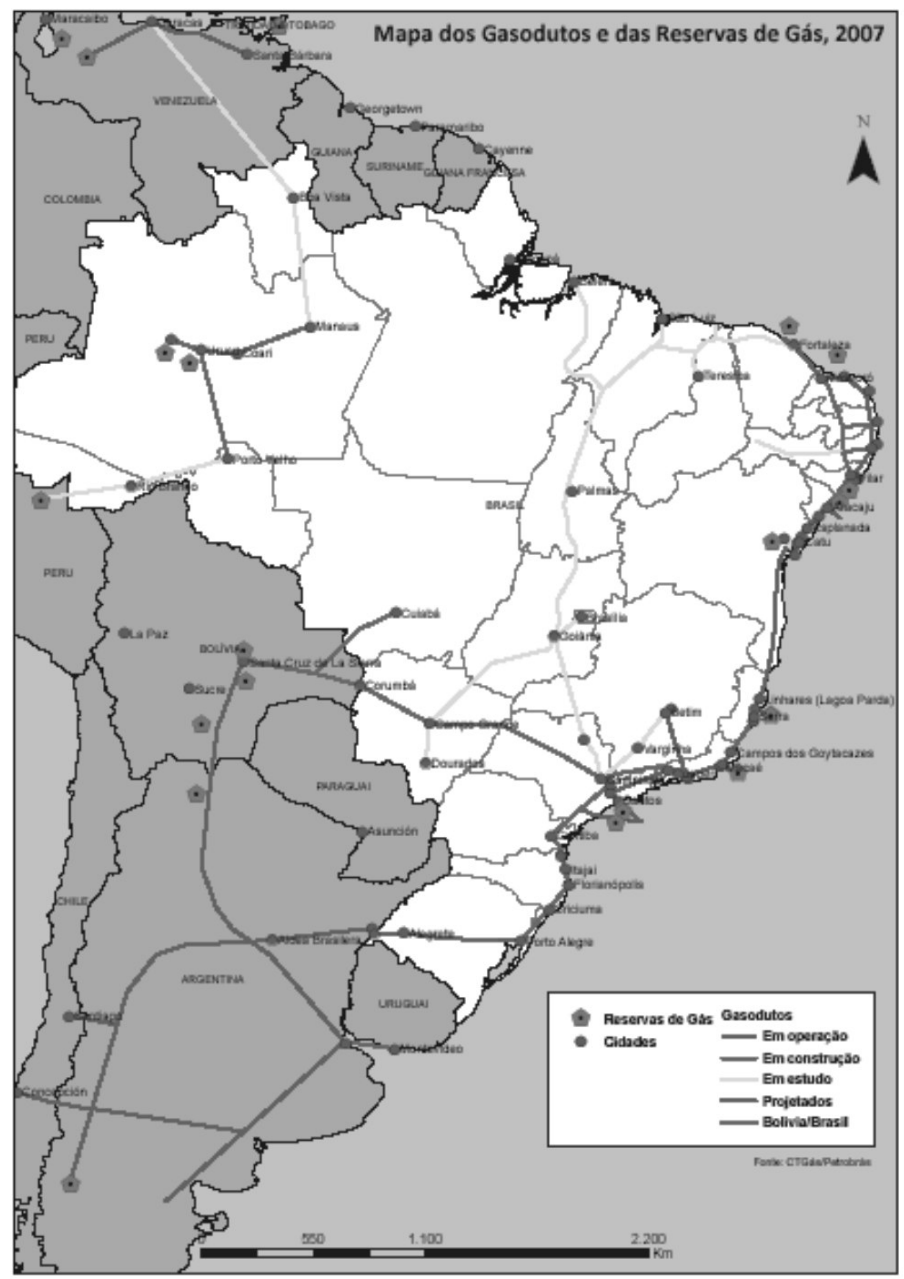

Mapa : Gasodutos no Brasil (2007).

Quanto à exploração de gás no Amazonas, em Coari, não há ainda como considerar a existência de um eixo de integração, havendo somente uma linha de distribuição entre os municípios de Coari e Urucu, sem estabelecer integração com outras regiões brasileiras. Estão em construção novos gasodutos para a distribuição de gás das jazidas de Juruá e Coari, o que ampliará a rede de distribuição de gás entre Urucu e Porto Velho, Juruá e Urucu, e Coari e Manaus. Em estudo, há tanto a possibilidade de ampliar a rede de gasodutos internamente, com a implantação dos trechos Manaus-Boa Vista e Porto Velho-Rio Branco, quanto a possibilidade de integrar essa região à Venezuela e ao Peru, podendo constituir-se um novo eixo de integração do setor de gás na Pan-Amazônia. 
No que se refere aos gasodutos em estudo (ver Mapa 2), importa, ainda, fazer referência àqueles trechos que deverão ligar a porção oriental da Amazônia às regiões Nordeste, Centro-Oeste e Sudeste. Caso esse projeto seja concretizado, o território nacional estará interligado por meio da rede de transporte de gás natural, articulando as principais regiões.

Além das medidas visando a antecipação da produção, estão sendo realizados investimentos de cerca de US $\$ 100$ milhões para reduzir a queima de 5,2 milhões de $\mathrm{m}^{3} / \mathrm{d}$ de óleo que acontece sobretudo na Bacia de Campos. Com isso o percentual de aproveitamento do gás, que hoje é de 86\%, chegará a 92\% até 2010. Simultaneamente e visando uma maior diversificação das fontes de abastecimento, o Brasil está construindo dois terminais de regaseificação de gás liquefeito importado, sendo um deles próximo a Fortaleza, no Estado do Ceará e outro na Baía de Guanabara, no Rio de Janeiro (RABINOVICH, 2007, p. 19).

Além dos efeitos positivos apontados nos itens anteriores, a crise do gás teve um importante papel ao expor as limitações do setor energético brasileiro. De fato, de acordo com Pinguelli Rosa, a partir da década de 90, a pífia ampliação do parque de geração hidráulica fez a expansão do setor elétrico apoiar-se na construção de usinas a gás (Carta Capital de 14/11/07). 


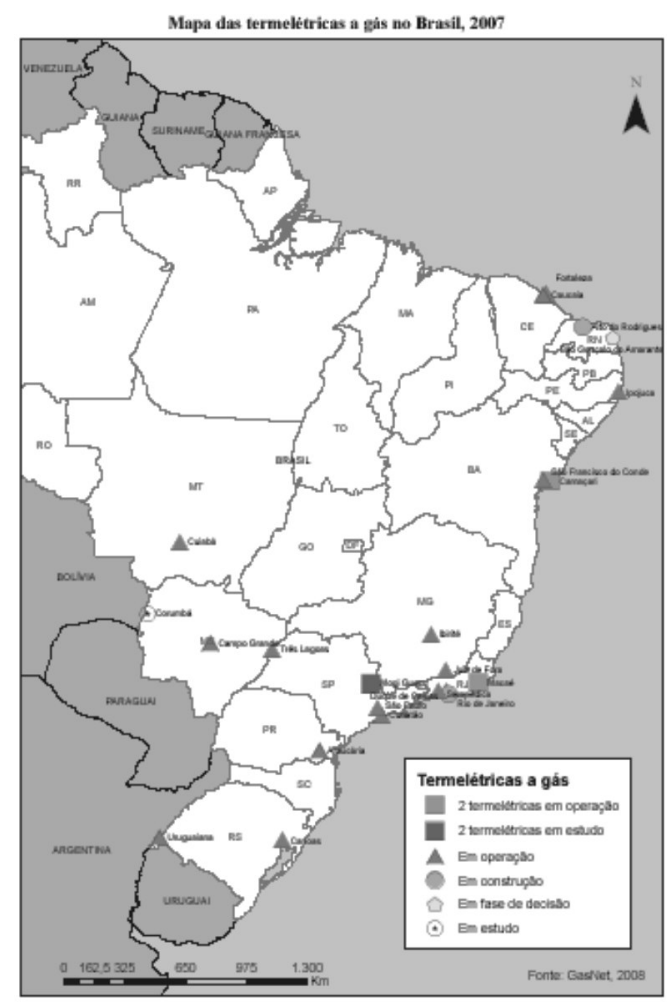

Mapa 3: Mapa das termelétricas a gás no Brasil (2007).

A superposição dos mapas das termelétricas a gás (Mapa 3) e do mapa de gasodutos permite que se faça a leitura da espacializadade da indústria do gás no Brasil. Entre meados dos anos de 90 e meados dos anos 2000, o que se viu foi uma ampliação do setor do gás no Brasil, dotando o território da infraestrutura energética necessária ao seu contínuo desenvolvimento, bem como o estabelecimento de maiores laços comerciais entre o Brasil, a Bolívia e a Argentina - laços que serão, futuramente, estabelecidos com a Venezuela e o Peru.

\section{OBSTÁCULOS E PERSPECTIVAS: UMA SÍNTESE}

Dado que o crescimento sustentável de qualquer economia tem como um dos seus mais relevantes pilares a segurança do abastecimento energético, torna-se basilar o conhecimento das principais fontes alternativas que podem ser colocadas a serviço da população. Como insumo essencial a um vasto conjunto de atividades econômicas e sociais, a energia desempenha papel importante na esfera distributiva 
entre indivíduos, setores produtivos e regiões. Em função de sua capilaridade no interior da estrutura produtiva, por tratar-se de um insumo básico, seus preços têm um impacto significativo nos índices de preços em geral. Portanto, dispor de energia barata proveniente de fontes diversificadas, além de garantir segurança, representa um fator determinante na competição capitalista, definindo muitas vezes os ganhadores ou os perdedores da concorrência internacional.

A indústria de gás brasileira apresenta algumas características importantes que, até o presente, têm limitado seu uso de modo mais abrangente: (i) cerca de $75 \%$ da produção nacional vêm de campos de gás associado ao petróleo, de reservatórios offshore; (ii) cerca de 60\% do gás não associado encontram-se em reservatórios offshore; (iii) o gás importado da Bolívia também tem um custo de oportunidade elevado, dada a grande distância dos centros de consumo no Brasil e não existe capacidade de estocagem fora dos próprios dutos; (iv) o gás não associado onshore encontra-se basicamente no sistema isolado da região Amazônica, sem possibilidade de interligação com o Nordeste ou o Centro-Sul do país, ao menos por enquanto.

A produção de gás, contudo, é apenas um item da agenda energética do Brasil. Neste início de século, o país ampliou consideravelmente sua produção de petróleo e de cana-de-açúcar para a produção de combustíveis, tendo assumido um papel de destaque nas discussões sobre bioenergia, além de estar ampliando investimentos na construção de novas hidrelétricas e em energia nuclear.

Se, a curto prazo, a instabilidade do abastecimento de gás trouxe prejuízos e descontentamentos a setores específicos da sociedade brasileira, a médio e a longo prazos, seguramente trará benefícios à economia nacional. Graças à aceleração das pesquisas no setor, novos efeitos multiplicadores têm ocorrido na indústria parapetroleira, o que, mais uma vez, legitima a opção brasileira pelo desenvolvimento de pesquisa tecnológica nacional autônoma sobre o abastecimento energético.

Em relação a esse último aspecto, em novembro de 2007, a Petrobras anunciou que testes confirmaram a existência de uma megajazida de petróleo na Bacia de Santos, incrustada a $7.000 \mathrm{~m}$ de profundidade, na camada pré-sal. Esse campo, denominado Tupi, poderá elevar em até $40 \%$ o potencial de extração de petróleo do país. Dois meses após o anúncio da reserva de Tupi, novamente a Petrobras veio a público comunicar a descoberta de uma grande jazida de gás natural, também na camada pré-sal, em águas de profundidade de $5.250 \mathrm{~m}$, a 37 quilômetros a leste de Tupi e a 290 quilômetros da costa. Mais uma vez, a empresa conseguiu um novo feito mundial: rompeu nova barreira tecnológica em matéria de extração em águas profundas - é a primeira empresa a perfurar em águas 
ultraprofundas. A descoberta de Tupi é só a primeira parte de um processo que vai demandar anos de trabalho e bilhões em investimentos, pois, de acordo com a Petrobras, o campo só deverá começar a produzir em 2013.

Desde o início de 2008, o governo boliviano tem tentado obter do governo brasileiro a flexibilização de seu contrato de 30 milhões de metros cúbicos diários de gás, de modo a permitir o aumento das vendas para a Argentina, cujo contrato prevê o fornecimento de 7,7 milhões de metros cúbicos diários, e a Bolívia só tem entregado 2,5 milhões. Os negociadores bolivianos argumentam que a insuficiência da oferta de gás é apenas temporária e que nos próximos anos o país poderá cumprir os compromissos assumidos.

Segundo Egler (2008, p. 161), a expansão da demanda de energia no mercado global também afetou diretamente a geoeconomia da América do Sul, com complicações políticas notórias. Entre Chávez, Morales e Rafael Correa, existe mais do que as propostas de esquerda e a retórica contra o Império. Venezuela, Bolívia e Equador são países exportadores de energia que estão nacionalizando suas reservas e instalações energéticas como instrumento para ampliar a margem de negociação com as grandes corporações multinacionais e transferir parte crescente das receitas do petróleo e do gás natural para o aparelho do Estado.

É, portanto, bem-vinda a iniciativa de buscar contornar as disputas políticas na América Latina fugindo do tratamento conjuntural quanto às carências energéticas e enfrentando a questão de modo estrutural. Nesse sentido, Brasil, Argentina e Bolívia estão elaborando um plano de integração energética que prevê a construção de cinco usinas hidrelétricas binacionais, sendo três com a Argentina e duas com a Bolívia. Nessa integração energética, Brasil e Argentina pretendem unir-se ainda para a criação de uma usina binacional de enriquecimento de urânio. Em relação à produção de gás natural, o Brasil busca estreitar laços comerciais com a Venezuela e com o Peru, ligando as jazidas desses países às áreas de consumo do nosso - interligação prevista para a terceira década do século XXI. Portanto, a questão energética latino-americana tem, de fato, requerido um tratamento de longo prazo, com acordos ao abrigo das instabilidades políticas ainda comuns nos países da região, onde os aspectos de integração energética permanecem fortemente subordinados às estratégias nacionais.

\section{REFERÊNCIAS}

ALMEIDA, Edmar de. Crise do gás boliviano e o futuro da indústria de gás natural no Brasil. Boletim Infopetro, Rio de Janeiro, p. 3-5, mar./abr. 2006. 
BRASIL. Ministério de Minas e Energia. Agência Nacional do Petróleo, Gás Natural e Biocombustíveis. Anuário Estatístico Brasileiro do Petróleo, Gás Natural e Biocombustíveis 2008: Seção 1, Tabela 1.6. Disponível em: <http:/ / www.anp.gov.br/conheca/anuario_2008.asp>. Acesso em: dia mês abreviado (exceto maio) ano.

CAETANO FILHO, Elísio. O papel da pesquisa nacional na exploração e explotação petrolífera da margem continental na Bacia de Campos. In: PIQUET, Rosélia (Org.). Petróleo, royalties e região. Rio de Janeiro: Garamond, 2003. p. 39-94.

DAMIANI, Rodrigo Souza. Indústria do petróleo: mola propulsora ou enclave econômico? 2007. 92 f. Dissertação (Mestrado em) - Universidade Candido Mendes, Campos dos Goytacazes, 2007.

DUTRA, Luís Eduardo Duque. A questão boliviana, segundo a lógica clássica e dentro do contexto histórico. Boletim Infopetro, Rio de Janeiro, p. 4-9, maio/ jun. 2006.

EGLER, Cláudio. As Américas: singularidade de um continente plural. In: OLIVEIRA, Marcio Piñon; COELHO, Maria Celia Nunes; CORRÊA, Aureanice de Mello (Org.). O Brasil, a América Latina e o mundo: espacialidades contemporâneas. Rio de Janeiro: Lamparina; ANPEGE; FAPERJ, 2008. p. 142-167. ORGANIZAÇÃO NACIONAL DA INDÚSTRIA DO PETRÓLEO. Plano de Antecipação de Produção de Gás. Disponível em: <http//www.onip.org.br/ arquivos >. Acesso em: 28 abr. 2008.

PINTO JUNIOR, Helder Queiroz. Dependência e vulnerabilidade energética: o caso do gás natural no Brasil. Boletim Infopetro, Rio de Janeiro, p. 7-10, mar./ abr. 2006.

PINTO JUNIOR, Helder Queiroz et al. Economia da energia: fundamentos econômicos, evolução histórica e organização industrial. Rio de Janeiro: Elsevier, 2007. 343 p.

PIQUET, Rosélia. Indústria do petróleo e dinâmica regional: reflexões teóricometodológicas. In: PIQUET, Rosélia; SERRA, Rodrigo (Org.). Petróleo e região no Brasil: o desafio da abundância. Rio de Janeiro: Garamond, 2007.

PIQUET, Rosélia. Impactos de um setor de alta tecnologia em uma região 
brasileira: o norte fluminense na era do petróleo. In: COLOQUIO SOBRE TRANSFORMACIONES TERRITORIALES, 5., 2004. Anais... La Plata: Universidad Nacional de La Plata, 2004. p. ...-...

RABINOVICH, Gerardo. Gas en América Latina: panorama político y económico. Boletim Infopetro, Rio de Janeiro, p. 18-21, jul./ago. 2007.

RAPPEL, Eduardo. Tendências do setor de petróleo e gás no Brasil: oportunidades e desafios para os fornecedores de bens e serviços. In: PIQUET, Rosélia; SERRA, Rodrigo (Org.). Petróleo e região no Brasil: o desafio da abundância. Rio de Janeiro: Garamond, 2007. p. 111-136.

ROSA, Luiz Pinguelli. Título da matéria. Carta Capital, Local de publicação, ano ..., n. ..., p. ...-..., 14 nov. 2007.

TORRES FILHO, Ernani Teixeira. O gasoduto Brasil-Bolívia: impactos econômicos e desafios de mercado. Revista do BNDES, Rio de Janeiro, v. 9, n. 17, p. 99-116, 2002. 